\title{
INTERDISCIPLINARY SURGICAL AND ORTHODONTIC TREATMENT OF ODONTOGENIC KERATOCYST OF THE MANDIBULAR BODY IN A 12-YEAR-OLD FEMALE PATIENT, WITH A RELAPSE AFTER 7 YEARS OF OBSERVATION: A CASE REPORT
}

\author{
Maciej Rączkiewicz', Monika Parchańska-Kowalik², Wojciech Stós², Jadwiga Stypułkowska', Bartłomiej W. Loster² \\ 'Department of Oral Surgery, Dental Institute, Medical Faculty, Jagiellonian University, Medical College, Cracow, Poland \\ ${ }^{2}$ Department of Orthodontics, Dental Institute, Faculty of Medicine, Jagiellonian University Medical College, Cracow, Poland
}

\begin{abstract}
Odontogenic keratocyst, until recently known as keratocystic odontogenic tumor, is a developmental, odontogenic cyst originating from a dental follicle. It is characterized by aggressive and quite fast growth, with a high tendency of recurrence (about $62 \%$ of cases). The following article presents a full description of interdisciplinary surgical-orthodontic treatment of a patient who, at the age of 12 , was diagnosed with a large keratocyst of the medial region of the mandible, including unerupted teeth: 43, 44, and 45. In addition, partial retention of teeth 23 and 35 was found. Surgical treatment was performed using a two-stage method, with a 7-year follow-up period, during which impacted tooth 43 was removed, and teeth 24 and 36 were also removed. During orthodontic treatment, the acrylic plug was placed in the fenestration area, further orthodontically assisted eruption of dislocated by the cyst teeth 44 and 45 , with the use of a removable orthodontic appliance and subsequently, the alignment of the upper and lower teeth with fixed appliances. After completion of orthodontic treatment, 7 years after the cyst enucleation, radiological examination was performed, which revealed a circular lesion in the projection of the roots of the lower teeth with a diameter of about $8 \mathrm{~mm}$, suggesting the presence of cyst relapse. The lesion was enucleated, and the result of the histopathological examination confirmed the diagnosis.
\end{abstract}

KEY WORDs: odontogenic keratocyst (OKC), cystis primordialis (PC), keratocystic odontogenic tumor (KCOT), impacted teeth, two-stage method (decompression, enucleation).

J Stoma 2018; 71, 4: 373-380

DOI: https://doi.org/10.5114/jos.2018.83412

\section{INTRODUCTION}

The classification of tumors and odontogenic cysts, commissioned by the World Health Organization (WHO) by Kramer, Pindborg, and Shear in 1992, classified the keratinizing cyst as an epithelial, developmental, odontogenic cyst of jaw bone [1]. In 2005, the World
Health Organization changed the classification of many items from 1992, including the keratocyst (primary cyst) to the group of benign tumors as a keratocystic odontogenic tumor (KCOT). This change was made on the basis of the following clinical, genetic, and immunohistochemical features: aggressive nature of growth, presence of satellite microcysts, tendency to infiltrate surrounding

\section{JOURNAL OF} STOMATOLOGY CZASOPISMO STOMATOLOGICZNE

AdDress for CORResPondence: Dr. Monika Parchańska-Kowalik, Department of Orthodontics, Dental Institute, Faculty of Medicine, Jagiellonian University Medical College, 4 Montelupich St., 31-155 Cracow, Poland, phone/fax: +48 1242454 02, e-mail: mkowalik137@gmail.com 
structures, documented cases of solid tumor, high recurrence rate, increased mitotic activity and lining proliferative index, mutations within the $\mathrm{PTCH}$ gene, and the association with Gorlin-Goltz syndrome [2-4]. Classification of the above lesion to the group of cysts or odontogenic tumors is still a subject of controversy because the WHO criteria for including it in the group of tumors in 2005 proved to be insufficient and undermined. The current guidelines of the WHO, presented in the $4^{\text {th }}$ edition of the "WHO Classification of Head and Neck Tumors", restored the nomenclature from 1992, reclassifying it to the group of odontogenic cysts as an odontogenic keratocyst (OKC) [5-7]. Peak incidence in $\mathrm{OKC}$ is observed in patients between 10 and 20 years of age, being twice as common in men as in women and predilection for Caucasian race. The most frequent location of keratocysts is the mandible, less often in the maxilla. A characteristic feature of the lesion is that it does not give clinical symptoms for a long time and is therefore often accidentally detected during routine X-ray examinations, for example during planning of orthodontic treatment. The keratocyst is characterized by aggressive growth with adjacent tissue destruction, spreading initially within the cancellous bone, and when it reaches large size, pain and Vincent's symptoms in the mandible may occur. Noticeable is the distension of the bone, dislocation or impaction of the surrounding teeth, much less the resorption of their roots. Two types of OKC are histologically distinguished: parakeratotic type and ortokeratotic type, with parakeratotic type more often observed, which shows greater local aggressiveness and tendency to relapse. In the radiological image, the characteristic feature of this cyst is the presence of an uni-
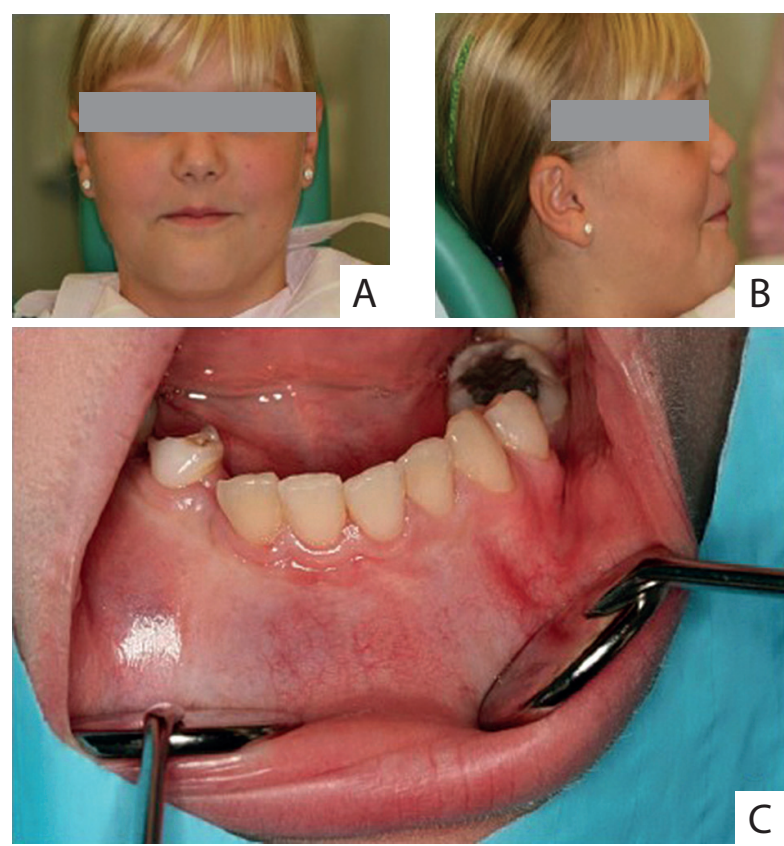

FIGURE 1. Extraoral and intraoral photographs prior to treatment locular osteolytic lesion, with clear sclerotic border in the initial stage of growth. More advanced cyst presents a multilocular form, and the sclerotic border is blurred. Quite often inside the cystic lesion, a retained tooth or teeth are located $[3,4,8]$. Keratocysts are removed surgically, but very often additional interdisciplinary procedures such as surgical, orthodontic, and in some cases, prosthetic are required. The diagnosis is based on a clinical examination, radiological image and above all, on the result of histopathological examination [3]. The type of surgical treatment depends on many factors such as patient's age, location, and size of the cyst. It may include radical procedures, aggressive methods, and conservative treatment. The radical procedures consist of the resection of the bone covered by the lesion, with a margin of healthy bone tissue. This is the most effective method, however, the least frequently used. It is aggressive and mutilating treatment, and especially in case of developmental age of patients, it may have adverse clinical and psychological implications. Aggressive methods contain enucleation of the lesion, which expands radicality of the treatment, with the use of chemical curettage and incorporation into the cyst cavity Carnoy's solution or liquid nitrogen during peripheral ostectomy. The least effective in terms of the risk of relapse are conservative methods, which include simple enucleation of the cyst, marsupialisation, or a two-stage method involving decompression of the cyst in the first stage of treatment, and then removal of cyst residues after reduction of the bone defect. The two-stage method is recommended in patients with very extensive cysts with a risk of iatrogenic fracture of the mandible and in patients at developmental age.

\section{CASE REPORT}

A female patient aged 12 years and 7 months, was referred to the Department of Oral Surgery, Jagiellonian University in Cracow by a general dentist, who was concerned about the enlargement of the patient's chin on the right side (Figure 1A-B). Intra-oral examination revealed distension of the mandibular body and lack of eruption of teeth: 43,44 , and 45 , and the present deciduous tooth 84 , in the presence of the teeth of the opposite side (teeth: 33, 34). Also, the slight inclination of the crowns of the incisors and the left mandibular canine to the right were noticeable (Figure 1C). It was found that the teeth 23 and 35 were unerupted. The patient did not report any complaints or sensation disorders. The evaluation of the orthopantomogram showed a large, unilocular osteolytic cystic lesion with the present sclerotic border, reaching from the area of the impacted tooth 45 , crossing the median line up to the apex of the root of tooth 34 . In the cyst cavity, impacted teeth were present: $43,44,45$, teeth 41 and 42 were set in distoinclination, and teeth 31-33 in mesioinclination (Figure 2A). 

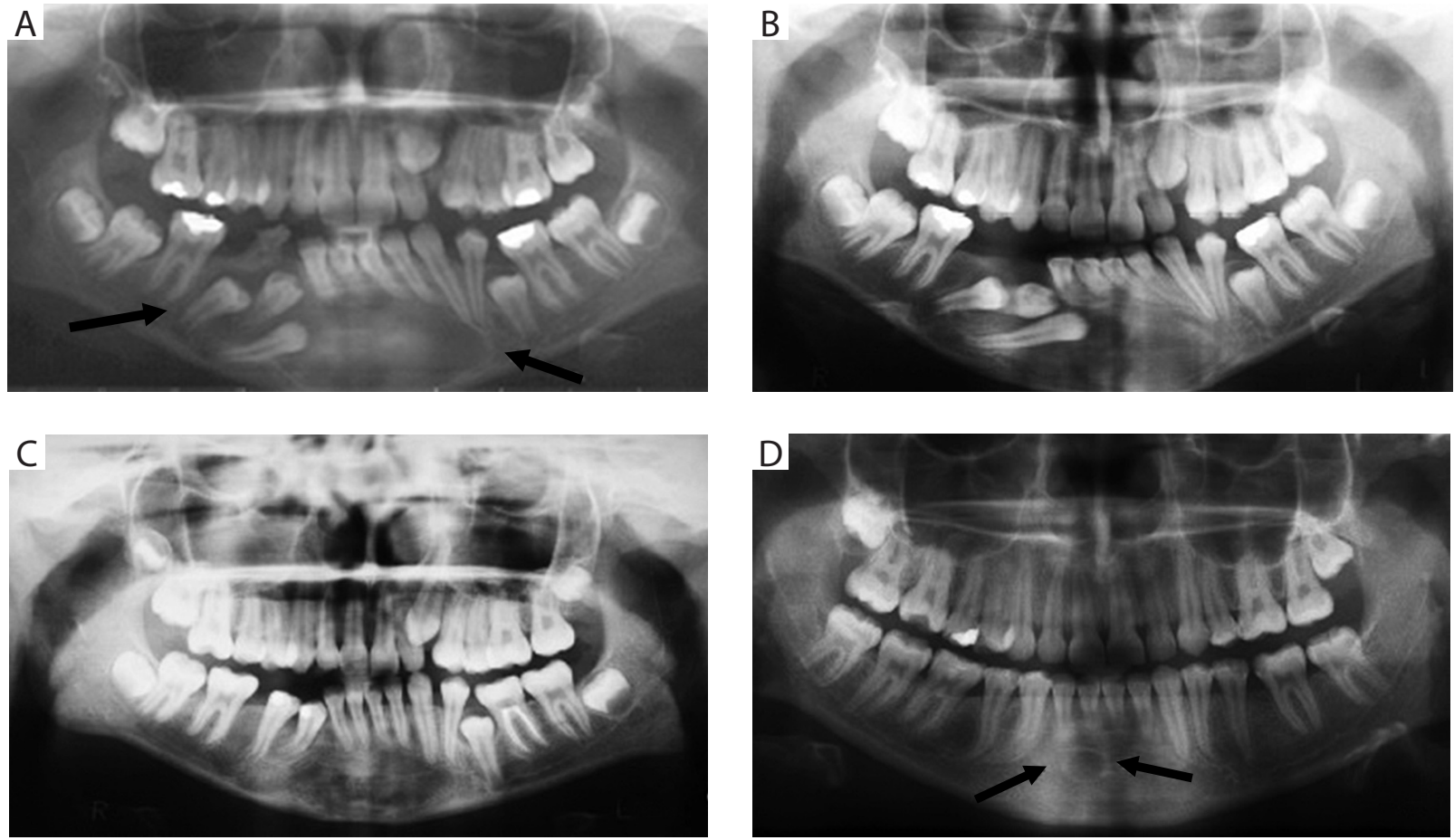

FIGURE 2. Orthopantomogram. A) Prior to treatment. B) Four months after decompression. C) Eight months after enucleation and extraction of tooth 43. D) After orthodontic treatment - visible recurrence of odontogenic keratocyst near the roots of teeth 41 and 42
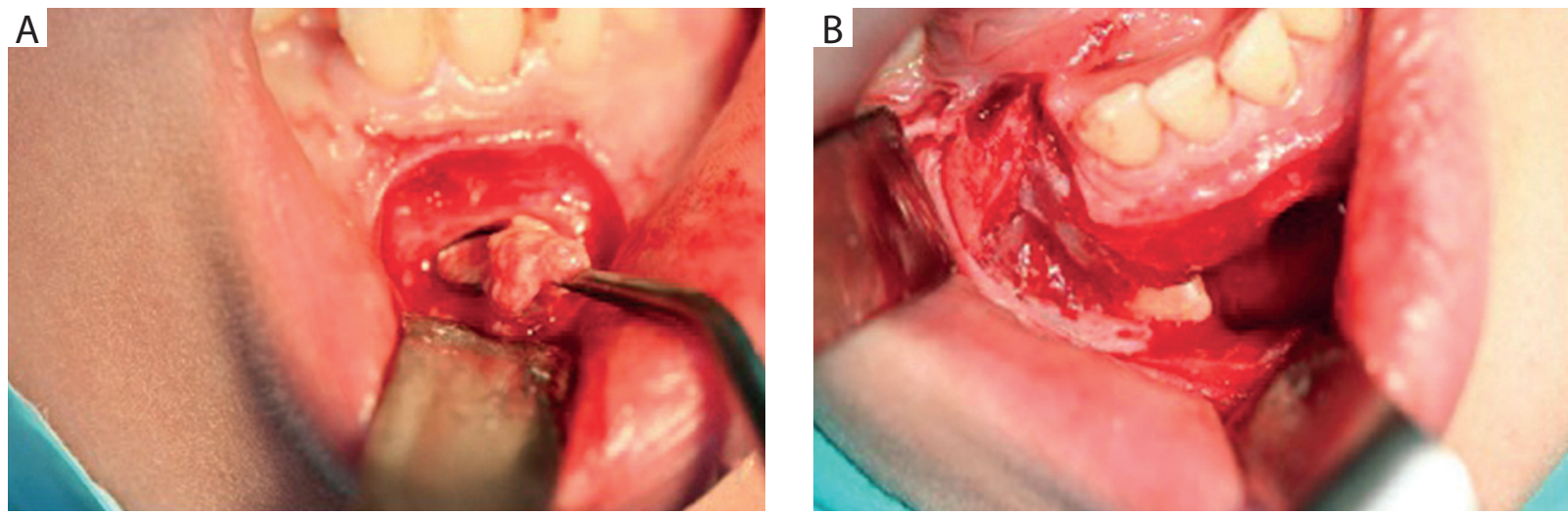

FIGURE 3. First stage of surgical treatment - decompression of the cyst. A) Visible horn masses. B) Visible horizontal position of the tooth 43

\section{TREATMENT}

Surgical treatment was started from the removal of the cyst wall under local anesthesia. Histopathological examination revealed the presence of a KCOT. A combined surgical-orthodontic treatment was planned. Surgical procedures included conservative treatment, the use of the two-stage method. In the first stage of surgical treatment, decompression of the cyst was performed with removal of the bone over the retained teeth crowns 43,44 , and 45 , with simultaneous extraction of the persistent deciduous tooth 84 , and the use of an acrylic plug until the second stage was per- formed, i.e., enucleation of the cyst (Figure 3A-B). After decompression, orthodontic treatment begun at the Orthodontic Department. The appliance lower plate with a labial arch with acrylic plug was used (Figure 4A-C). The result of the histopathological examination confirmed the previous diagnosis: a KCOT, a parakeratotic type. Four months after decompression of the cyst, a control orthopantomographic X-ray was performed showing significant displacement of tooth buds 43,44 , and 45 towards the occlusal plane and a reduction of the lesion with visible partial bone tissue regeneration (Figure 2B). The next stage of the surgical and orthodontic treatment was the redecompression and widening of the decom- 

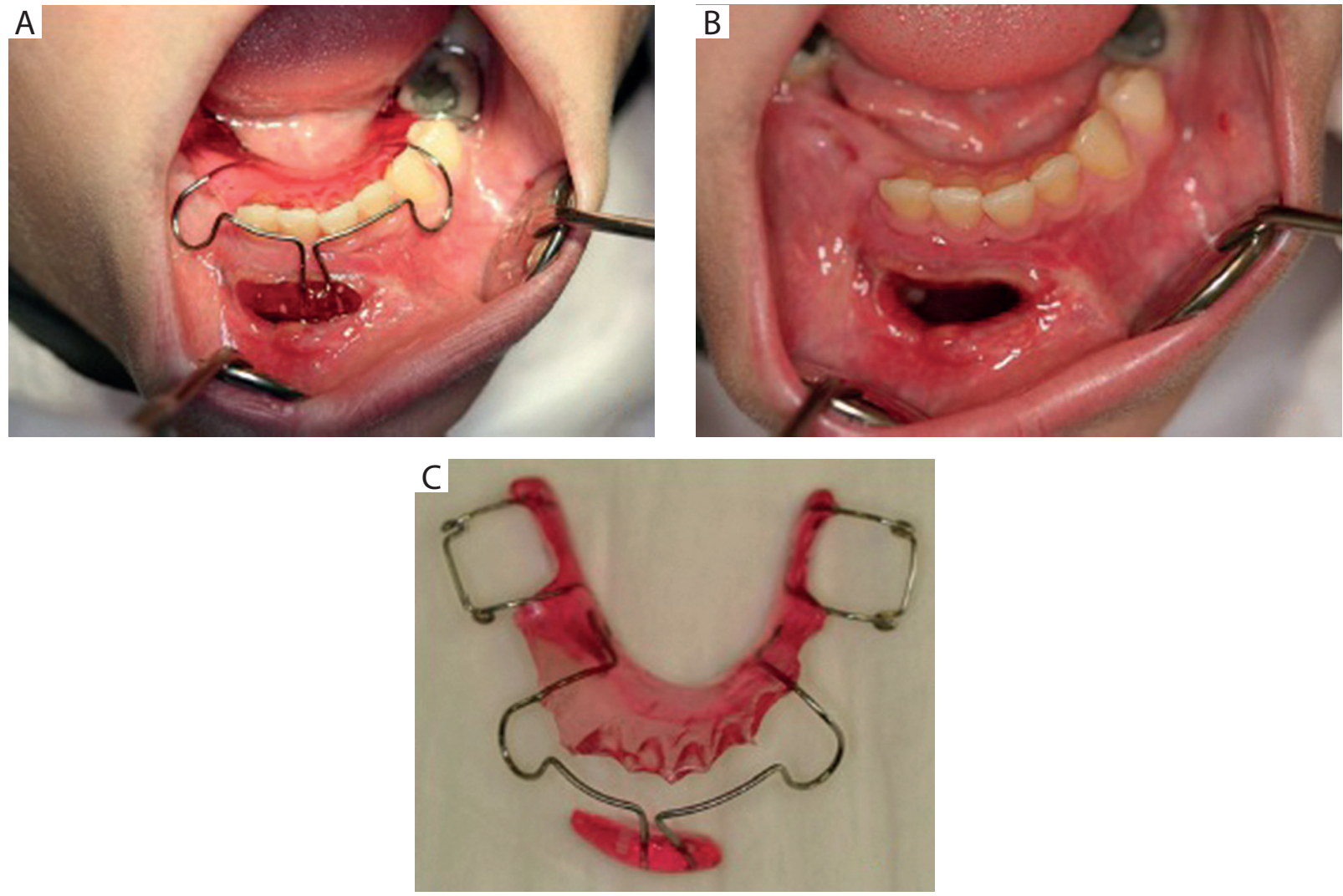

FIGURE 4. The use of the lower acrylic plate with a labial arch with an acrylic plug

pression aperture and bonding the orthodontic attachments, which was used to start incorporating teeth 44 and 45 into the dental arch (Figure 5A). A few days after the procedure, the orthodontic appliance was placed in the form of the lower Schwarz plate. For the purpose of orthodontic extrusion, elastic tractions stretched from the attachments on teeth 44 and 45 to hooks that were embedded in the acrylic plate were used. The extrusion force was measured at each control visit, for each of the extruded teeth a force was not exceeding 75 grams. The next stage of surgical treatment required cone beam computed tomography (CBCT) to determine the exact extent of the cyst before the enucleation procedure, and to assess the possibility to bring tooth 43 to the dental arch, whose horizontal position in the bone, along with the lack of space in the arch, led to the decision to extract it (Figure 6). After assessing the CBCT image, it was decided to extract the retained tooth 43 at the same time with complete enucleation of the cyst residue. Due to the presence of deep filling in tooth 36 , pulpitis occurred, and the patient was referred for endodontic treatment. Patient continued the orthodontic extrusion of teeth 44 and 45 using a removable appliance and the retained premolars appeared in the oral cavity (Figure 5B-D). A control orthopantomogram (OPG) (Figure 2C) showed complete bone regeneration in the cyst area. Also, a displacement towards the occlusal plane of teeth 44 and 45 , and verticalization of the inclined incisors were found. Orthodontic analysis of the space availability in the dental arches was performed and revealed no space for teeth 35 and 23 . A decision was made about hemisection of the tooth 36 and the extraction of the mesial root with a fragment of the crown, allowing incorporation of tooth 35 into the arch. Furthermore, it was decided to extract the tooth 24 due to total lack of space in the upper dental arch for retained tooth 23 . After four years of the procedure, a decision was made to start orthodontic treatment using fixed appliances, which aimed to align the teeth and the occlusal plane, and to obtain optimal tooth intercuspation. Cephalometric analysis was completed according to the rationalized Cephalometry of the Kracovia System in the Facad computer program, reviling the first skeletal class in the sagittal dimension, confirmed by ANB and Wits measurements. A slight prognathism of maxilla and mandible was found. The alveolar processes showed correct inclination and the upper and lower incisors were slightly proclaimed, while interincisal angle was reduced. The vertical relationship was within the norm. The mandible showed an anterior rotational pattern of growth. The analysis of the profile based on the cephalometrics showed that the upper and lower lips were set in a normal relation to the aesthetic line, the nasolabial angle was also normal, but the chin was clearly marked. Fixed orthodontic appliances in the Kracovia System was bonded in the upper and lower dental 

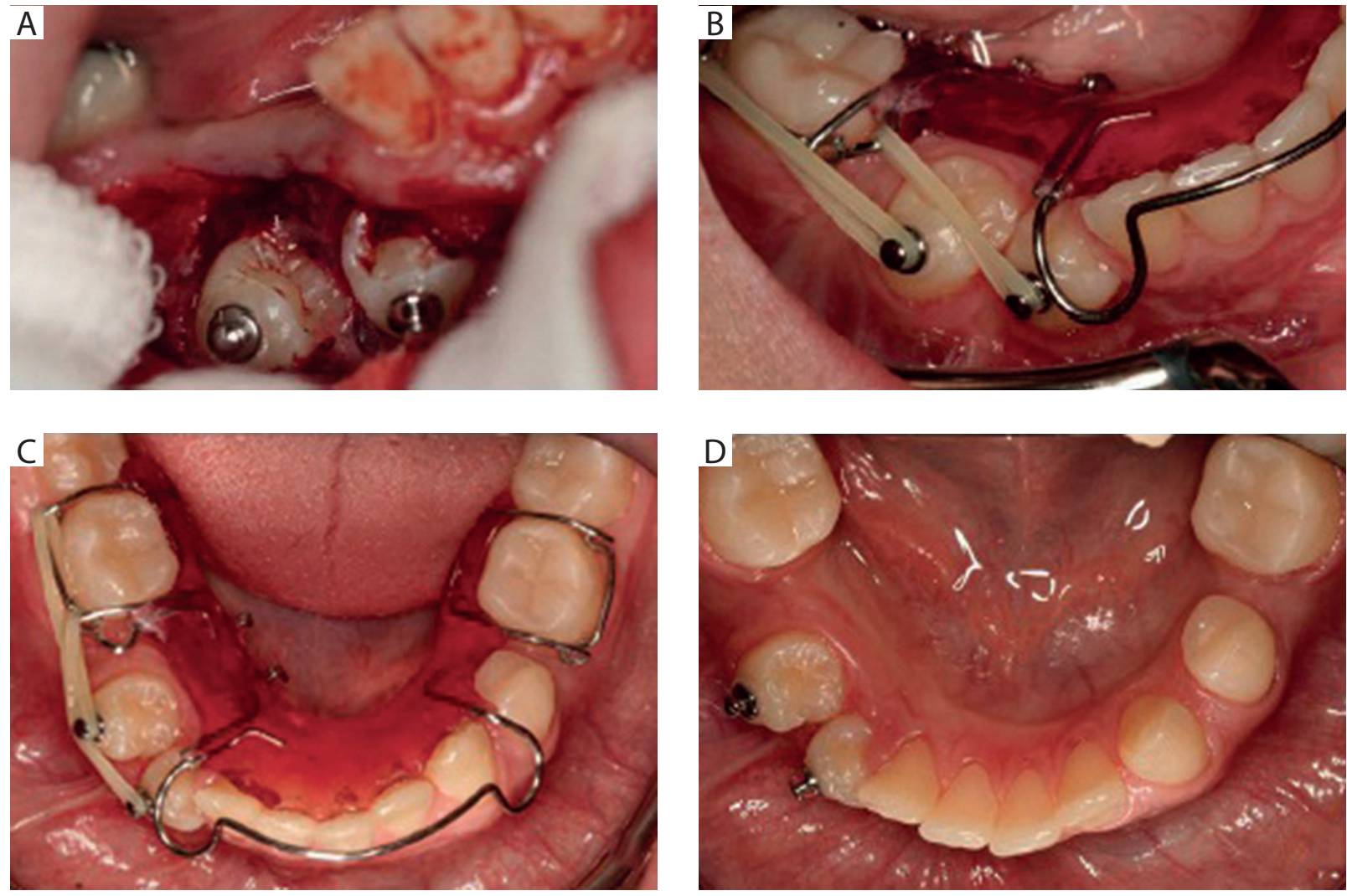

FIGURE 5. A) Bonding of orthodontic attachments during surgery. B-D) Orthodontic extrusion of teeth 44 and 45 with the use of removable orthodontic appliance

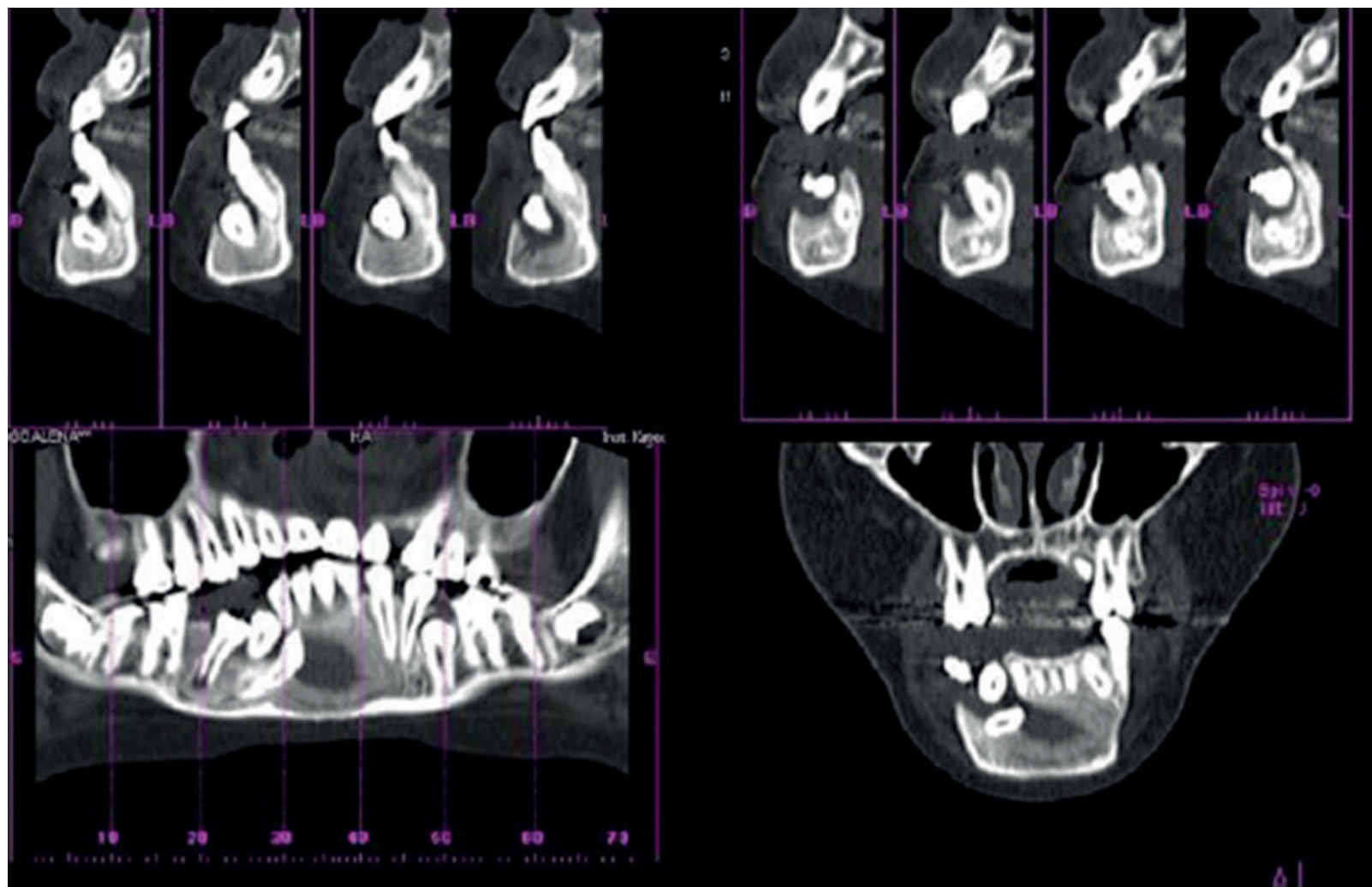

FIGURE 6. Cone beam computed tomography before cyst enucleation with extraction of tooth 43 

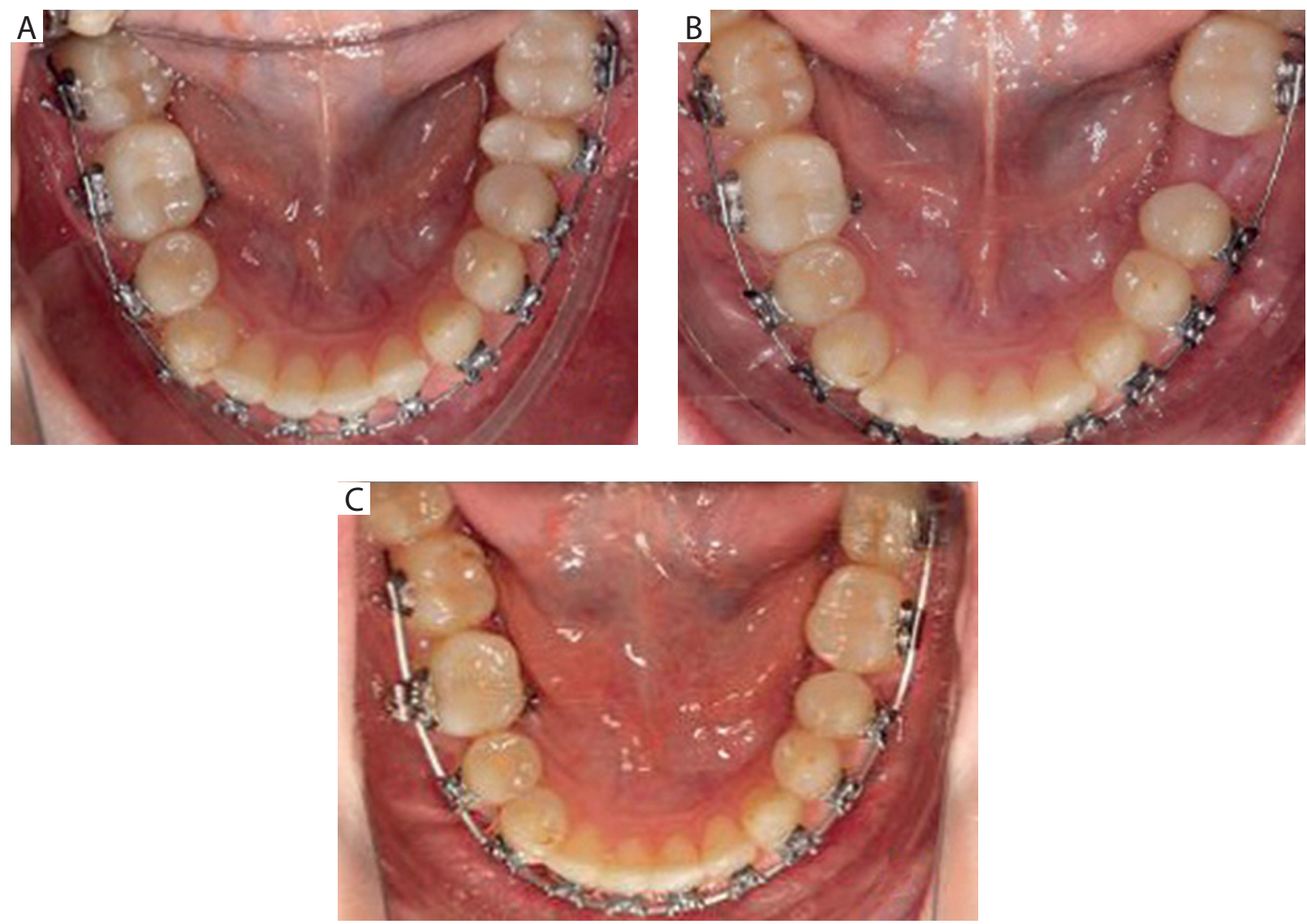

FIGURE 7. Photographs of mandibular arch. A) Visible distal part of the tooth 36 after hemisection. B) Condition after extraction of distal root of tooth 36. C) Condition after completed mesialization of teeth 37 and 38
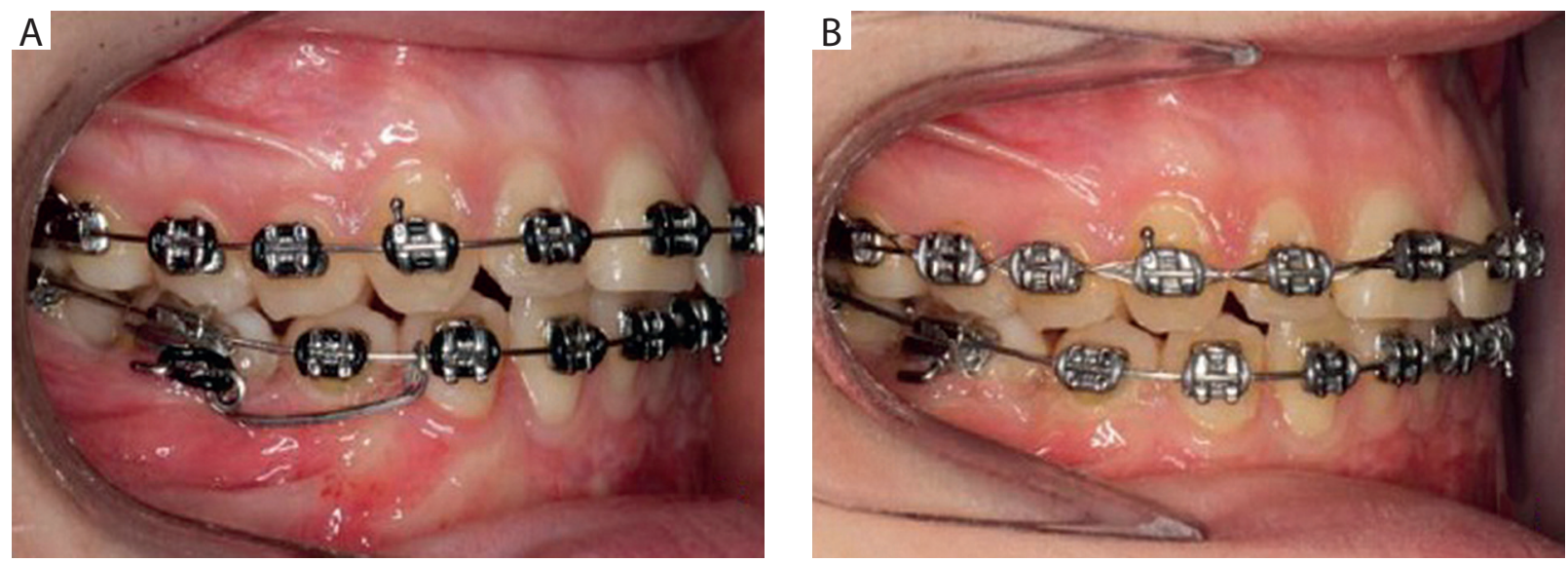

FIGURE 8. A) Cantilever made of TMA wire, used to verticalization of tooth 46. B) Condition after removal of the cantilever

arch. The sequence of the arch wires was: $014 \mathrm{NiTi}, 016$ NiTi, $018 \mathrm{NiTi}, 018$ ss, 17/25 NiTi, and 17/25 ss. After 9 months of treatment with fixed appliances, the decision was made to extract the distal root of tooth 36 to correct the lower midline and move to the arch tooth 38 . After the initial healing of the post-extraction wound, the mesialization of the tooth 37 started with the use of elastic chain, with the anchorage unit being the pa- tient's teeth. Six months after the extraction, the mesialization of the tooth 37 was obtained and the tooth 38 was visible in the oral cavity (Figure $7 \mathrm{~A}-\mathrm{C}$ ). Due to the mesioinclination of the tooth 46 , a cantilever was used for its upright, bent out of wire 017/025 TMA, mounted to the auxilary tube. The second lever arm rested on the primary arch (018 ss) near the premolars. After 6 months, the tooth 46 was uprighted without noticeable side effects 

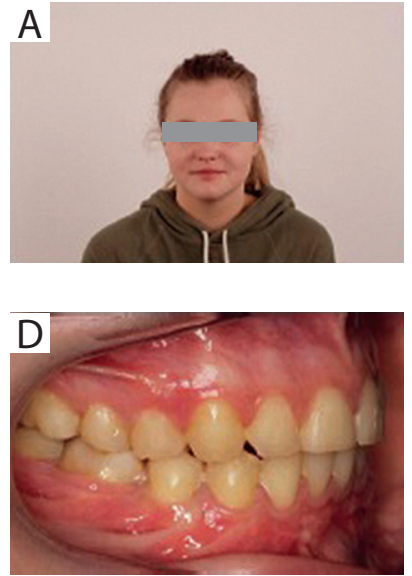
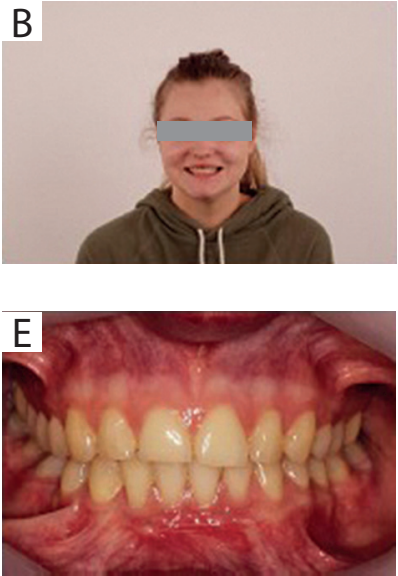
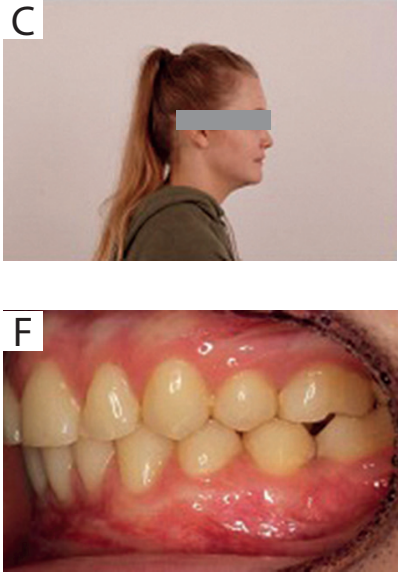
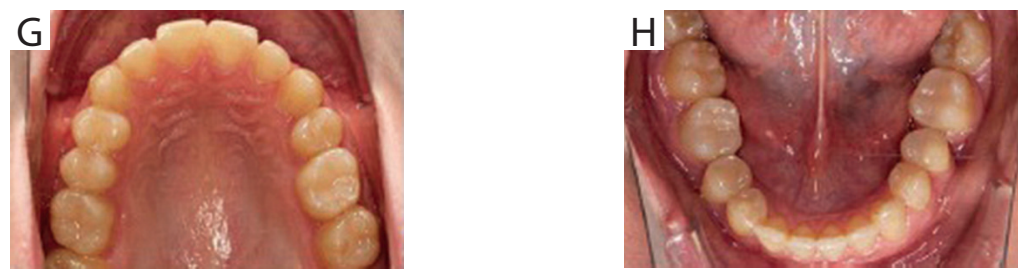

FIGURE 9. Extraoral and intraoral photographs after orthodontic treatment

in the form of premolar intrusion (Figure 8A-B). The treatment with fixed appliances lasted 2.5 years. The decision on its completion was made after optimal lateral tooth intercuspation and a satisfactory aesthetic effect (Figure 9A-H). After completion of the orthodontic treatment, 7 years after the cyst enucleation procedure, radiological control X-rays were performed, which revealed a small, circular clear in the projection of the roots of the lower incisors, suggesting the presence of local recurrence (Figure 2D). Intra-oral symptoms indicating the presence of the cyst were not found, the patient did not report any complaints. CBCT was performed, which confirmed the presence of a cystic lesion with a diameter of approx. $8 \mathrm{~mm}$ with a visible distinct sclerotic border (Figure 10). The lesion was enucleated, and the result of the histopathological examination confirmed the initial diagnosis.

\section{DISCUSSION}

Surgical procedures in patients at developmental age, who have been diagnosed with OKC, are still the topic of discussion. Removal of the whole cyst completely, with extraction of the teeth or tooth buds involved by the lesion, is a radical surgical treatment that gives the smallest percentage of relapses. However, if it is possible to preserve the teeth, considering the functional, aesthetic, and psychological aspects, the methods of conservative surgical treatment should be used as the method of choice $[3,12,13]$. The two-stage method of enucleating a cyst has been successfully used in the Department of Oral Surgery. The latest scientific report based on the analysis of 1,900 keratocysts treated

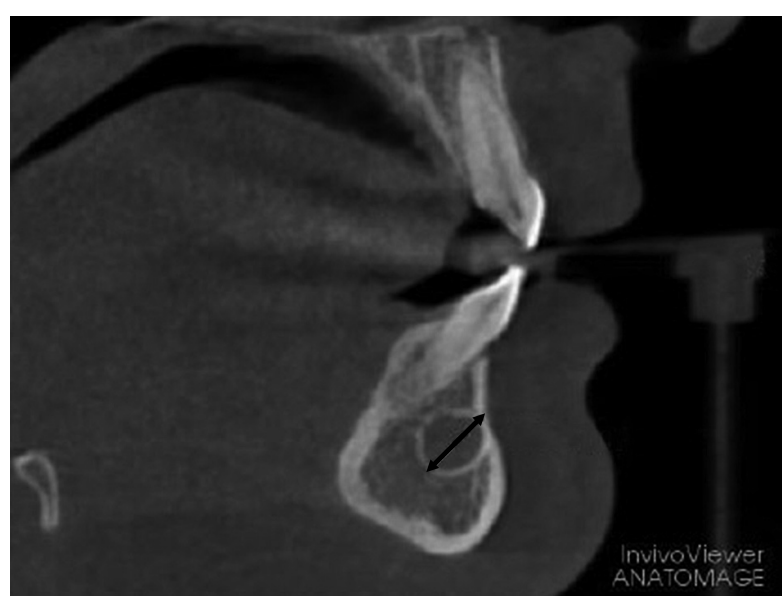

FIGURE 10. Cone beam computed tomography scan with visible local recurrence of odontogenic keratocyst

surgically with conservative methods such as decompression and enucleation as well as marsupialisation and enucleation, indicate a very good treatment effect. The percentage of cases cured was $88.1 \%$ and $82.2 \%$, respectively, with a 5-year observation period [14]. In patients treated at developmental age, follow-up examinations are recommended every 6 months [13]. In the case of the above-mentioned patient, the recurrence occurred approximately after 7 years from the moment of diagnosing and starting the two-stage treatment. In summary, the recurrence rates of OKC depends on many factors such as the treatment method, the size and location of the lesion, the presence of satellite microcysts, histological para- or ortokeratotic type, the length 
of the observation period, and the number of observed cases $[3-44,12,15]$. Orthodontic treatment of patients with extensive odontogenic cysts is a great therapeutic challenge, exemplary and close cooperation with the surgeon and the patient is required. In the domestic and foreign literature, only a few works can be found presenting a complete description of surgical and orthodontic treatment of patients due to keratocysts [12, 16]. In presented case, the lack of orthodontic intervention could be associated with loss of teeth 43, 44 and 45 , and the need for subsequent prosthetic treatment. In the course of the patient's orthodontic treatment, the hemisection of the tooth 36 was appropriate, as the extraction of the mesial root enabled the eruption of the impacted tooth 35, and extraction of the distal root in the second stage allowed to set tooth 38 into the arch. Finally, the staged removal of the tooth 36 prevented the atrophy of the alveolar bone and the use of fixed appliances provided optimal tooth position. Thanks to interdisciplinary cooperation, it was possible to achieve a very good therapeutic effect, both functional and aesthetic. It is worth emphasizing the active and long-term cooperation of a young patient in a complex, successful healing process.

\section{CONCLUSIONS}

Two-stage surgical treatment of extensive odontogenic cysts, especially in patients at developmental age, can be very effective, however, there is a risk of recurrence, which is most often caused by not complete enucleation or presence of satellite microcysts.

The two-stage method gives the possibility to preserve the surrounding teeth, which is extremely important especially in juvenile patients. The use of surgical radical methods is usually associated with the loss of teeth, located in the cyst cavity or its vicinity.

Treatment of extensive keratinizing cysts requires a combination of surgical, orthodontic, and sometimes prosthetic treatment. The presented case is a proof that thanks to very good interdisciplinary cooperation and the patient's involvement in the treatment process, a very good result can be obtained, both functional and aesthetic.

The keratocyst is usually formed between 10 and 20 years of age. Early detection of OKC and prompt treatment prevents the lesion from growing and improves the prognosis for full recovery.

Patients treated for OKC require regular radiological check-ups, due to the possibility of recurrence, even several years after the end of surgical treatment.

\section{CONFLICT OF INTEREST}

The authors declare no potential conflicts of interest with respect to the research, authorship, and/or publication of this article.

\section{References}

1. Kramer IRH, Pindborg JJ, Shear M. Histological Typing of Odontogenic Tumours. $2^{\text {nd }}$ ed. Springer-Verlag, Heidelberg 1992.

2. Barnes L, Eveson JW, Reichart P, Sidransky D. Pathology \& Genetics. Head and Neck Tumours. IARC Press, Lyon 2005.

3. Kaczmarzyk T, Stypułkowska J, Tomaszewska R, Czopek J. Nowotwory zębopochodne i guzy nowotworopodobne kości szczękowych. Wydawnictwo Kwintesencja, Warszawa 2009.

4. Kaczmarzyk T (ed.). Torbiele obszaru szczękowo-twarzowego. Wydawnictwo Kwintesencja, Warszawa 2015.

5. Wright JM, Vered M. Update from the $4^{\text {th }}$ edition of the World Health Organization Classification of Head and Neck Tumours: odontogenic and maxillofacial bone tumours. Head Neck Pathol 2017; 11: 68-77.

6. Kaczmarzyk T, Stypułkowska J, Tomaszewska R. Zmiany w klasyfikacji WHO guzów zębopochodnych i nowotworów kości szczękowych. J Stoma 2017; 70: 484-506.

7. Speight $\mathrm{P}$, Devilliers P, Li TJ, et al. Odontogenic keratocyst. In: El-Naggar AK, Chan JKC, Grandis JR, Takata T, Slootweg PJ (eds.). WHO Classification of Head and Neck Tumours. International Agency for Research of Cancer, Lyon 2017, p. 235-236.

8. Shear M, Speight P. Cyst of oral and maxillofacial regions. $4^{\text {th }}$ ed. Blackwell Munksgaard, 2007.

9. Pogrel MA, Jordan RC. Marsupialization as a definitive treatment for the odontogenic keratocyst. J Oral Maxillofac Surg 2004; 62: 651-655.

10. Wushou EA, Zhao YJ, Shao ZM. Marsupialization is the optimal treatment approach for keratocystic odontogenic tumour. J Craniomaxillofac Surg 2014; 42: 1540-1544.

11. Al-Moraissi EA, Dahan AA, Alwadeai MS, et al. What surgical treatment has the lowest reurrence rate following the management of keratocystic odontogenic tumour?: a large systematic review and meta-analysis. J Craniomaxillofac Surg 2017; 45: 131-144.

12. Deboni MCZ, Brozoski MA, Traina AA, et al. Surgical management of dentigerous cyst and keratocystic odontogenic tumor in children: a conservative approach and 7-year follow-up. J Appl Oral Sci 2012; 20: 282-285.

13. Kamil AH, Tarakji B. Odontogenic keratocyst in children: a review. Open Dent J 2016; 10: 117.

14. de Castro MS, Caixeta CA, de Carli ML, et al. Conservative surgical treatments for nonsyndromic odontogenic keratocysts: a systematic review and meta-analysis. Clin Oral Invest 2018; 22: 2089-2101.

15. Johnson NR, Batstone MD, Savage NW. Management and recurrence of keratocystic odontogenic tumour: a systematic review. Oral Surg Oral Med Oral Pathol Oral Radiol 2013; 116: e271-e276.

16. Lacarbonara M, Marzo G, Lacarbonara V, et al. Presentation of a keratocystic odontogenic tumor with agenesis: a case report. J Med Case Rep 2014; 8: 126. 